\title{
Cultivar discrimination at different site elevations with remotely sensed vegetation indices
}

\author{
Bruno Basso, ${ }^{1,2,3}$ Davide Cammarano, ${ }^{3}$ Giovanni Cafiero, 1 Stefano Marino, ${ }^{4}$ Arturo Alvino ${ }^{4}$ \\ 'Department of Crop Systems, Forestry and Environmental Sciences, University of Basilicata, \\ Potenza, Italy; ${ }^{2}$ Kellogg Biological Station, Michigan State University, Hickory Corners, MI, USA; \\ ${ }^{3}$ Institute for Sustainable Resources, Queensland University of Technology, QLD, Australia; \\ ${ }^{4}$ Department of Crop Production, Environmental and Animal Science (S.A.V.A.), University \\ of Molise, Campobasso, Italy
}

\begin{abstract}
The objectives of this study are to evaluate vegetation indices sensitivity to discriminate between two different cultivars; and to determine the effects of site elevation and developmental stages on cultivar discrimination. The experiment was carried out for the growing season 2007/08 at "Agro di Pesche" (Central Italy, Molise region). Four experimental fields were located at different elevation ranging between $590 \mathrm{~m}$ to $922 \mathrm{~m}$ above the sea level (asl). For each field, two potato (Soluanum Tuberosum L.) cultivars were used. Leaf area was collected through non-destructive measurements, and a hand-held spectroradiometer was used to measure the reflected light from the canopy of the two cultivars. Results from the ANOVA show that the ratio between MCARI (Modified Chlorophyll Absorption Ratio Index) and OSAVI (Optimized Soil Adjusted Vegetation Index), NDRE (Normalized Difference Red Edge) and MCARI were able to discriminate among cultivars at different site elevations. NDVI (Normalized Difference Vegetation Index) was not able to discriminate the two cultivars because of the influence of soil reflectance and leaves distribution.
\end{abstract}

Correspondence: Prof. Bruno Basso, Department of Crop Systems, Forestry and Environmental Sciences, University of Basilicata, via N. Sauro 85, 85100 Potenza, Italy.

Tel. +39.3204371042 - Fax: +39.0971 .205378 .

E-mail: bruno.basso@unibas.it

Key words: potato cultivar, vegetation indices, proximal sensing, elevation.

Received for publication: 28 January 2010

Accepted for publication: 10 May 2010.

CC Copyright B. Basso et al., 2011

Licensee PAGEPress, Italy

Italian Journal of Agronomy 2011; 6:e1

doi:10.4081/ija.2011.e1

This article is distributed under the terms of the Creative Commons Attribution Noncommercial License (by-nc 3.0) which permits any noncommercial use, distribution, and reproduction in any medium, provided the original author(s) and source are credited.

\section{Introduction}

Crop yield estimation at a regional level is influenced by crop cultivar because different cultivars have different maturity times; hence the discrimination of different crop cultivars with vegetation indices might help minimizing errors in yield prediction (Pfeiffer, 1996; Galvão et al., 2009). Crop yield estimation is important because its accurate prediction can affect farmers' economic planning, agronomic field management and yield price. Vegetation indices from remotely sensed data have been used to find functional relationship with crop yield at farm scale (Zhu et al., 2007).

Vegetation indices are linear combinations or ratios of red, green and infrared spectral bands; and they are designed to find functional relationship between crop characteristics and remote sensing observation (Wiegand et al., 1990). In agricultural research, vegetation indices have been found to be robust surrogates for traditional agronomic parameters, such as leaf area index (LAI), fraction of green cover, fraction of absorbed photosynthetically active radiation (fAPAR), crop biomass and crop nitrogen content (Asrar et al., 1984; Huete et al., 1985; Baret and Guyot, 1991; Qi et al., 1994; Aparicio et al., 2000; Inoue et al., 2003).

Daughtry and Walthall (1998) discriminated between herbaceous crops with measured and simulated remote sensing technique. They found that the green band $(550 \mathrm{~nm})$, the red $(670 \mathrm{~nm})$, the wavelength located at $720 \mathrm{~nm}$, which is in the "red-edge" position of the electromagnetic spectrum (Demetriades-Shah et al., 1990) and the nearinfrared $(800 \mathrm{~nm})$ discriminated the leaves of one herbaceous cultivar from the others. Galvão et al. (2005) used vegetation indices to discriminate among different sugarcane cultivars, finding that it was possible to identify one particular cultivar because of differences in canopy architecture and leaf orientation.

The use of vegetation indices in discriminating among genotypes for improving final yield has been proposed by Aparicio et al. (2000; 2002). They investigated if vegetation indices could adequately identify crop biomass and LAI as indirect selection criteria in breeding programs. They found that vegetation indices successfully tracked changes in LAI across a broad range of different growing stages, environment and genotypes. Thenkbail (2002) found that the discrimination between several agricultural crops was optimized at four different narrow bands located at 547, 675, 718 and $904 \mathrm{~nm}$.

Rolling terrain affects cultivar discrimination and crop yield with vegetation indices. Li et al. (2001) found that NDVI was affected by site elevation because of changes of wavelengths in red reflectance patterns. Basso et al. (2009) found that NDVI was affected by the interaction of topography and weather patterns, which influenced its ability to predict crop yield. 
Among the different vegetation indices the NDVI is the commonly used, but at values of LAI higher than 3 such index reaches a saturation point limiting its use in crop determination (Aparicio et al., 2000). And, at low canopy cover it is negatively influenced by soil reflectance (Huete et al., 1985).

Huete (1988) developed the Soil Adjusted Vegetation Index (SAVI) to reduce the effects of soil reflectance, such index is similar to the NDVI in its mathematical form except for a factor $L$ which is function of canopy cover; a value of 0.5 would reduce the effects of soil reflectance. Rondeaux et al. (1996) proposed the Optimized Soil Adjusted Vegetation Index (OSAVI), which is similar to the SAVI with the difference in the $L$ factor, which is set to be 0.16 . However, both indices showed the same limitation of the NDVI later in the season at high LAI values.

To reduce the influence of crop growth and being able to estimate crop nutritional deficiency, Barnes et al. (2000), based on the NDVI formula, developed the Normalized Difference Red-Edge Index (NDRE), they used reflectance in the red-edge portion of the electromagnetic spectrum, which is the spectral region between the red and near infrared. This index was successfully used to predict crop nitrogen concentration on cotton during the growing season (Barnes et al., 2000). It has never been used for crop cultivar discrimination. Nonetheless, the use of $790 \mathrm{~nm}$ and $720 \mathrm{~nm}$ instead of the red and near infrared, which are located on the slope of the red-edge, which is very sensitive to changes in canopy nutritional status, might be useful in detecting changes in crop growth as well (Demetriades-Shah et al., 1991).

The Modified Chlorophyll Absorption Ratio Index (MCARI; Daughtry et al., 2000), measuring the depth of chlorophyll absorption (670 nm) relatively to the reflectance at 700 and $550 \mathrm{~nm}$, might be also useful to discriminate between cultivar because of the use of green and red reflectance and reflectance are related to canopy "greenness" and canopy photosynthesis, and the red-edge position. In fact, the ratio $700 / 600 \mathrm{~nm}$ was introduced with the aim at reducing soil reflectance effects, and part of the crop that do not have photosynthetic capacity. From this index the Transformed Chlorophyll Absorption Reflectance Index (TCARI; Haboudane et al., 2002) was developed. It presents the same concepts of the MCARI, and as the previous index, it is influenced by low LAI values and also by soil reflectance (Haboudane et al., 2002).

The Triangular Vegetation Index (TVI; Broge and Leblanc, 2000) is based on the hypothesis that the green, red and near infrared reflectance form a triangle and its area increase as the photosynthetic pigments absorb light. It has been developed and tested on a simulated dataset, but its validation showed good results in estimating LAI and canopy chlorophyll. Therefore, it might be used to discriminate among different cultivars.

The hypothesis of this study are that cultivars grown at different site elevation have distinct spectral patterns throughout the growing season, and that vegetation indices will be able to detect the different cultivar growing conditions.

The objectives of this study were: i) to evaluate vegetation indices sensitivity to discriminate between two different cultivars; ii) to determine the effects of site elevation and developmental stages on cultivar discrimination.

\section{Materials and Methods}

\section{Site description}

The experiment was carried out for the growing season 2007/08 at "Agro di Pesche" (Central Italy, Molise region). Four experimental fields were located at different elevation ranging between $590 \mathrm{~m}$ to $922 \mathrm{~m}$ above sea level (asl) (Table 1). For each field, two potato (Soluanum Tuberosum L.) cultivars were used, Turchesca and
Desiree. Turchesca cultivar is a local variety and was declared "regional product" by the Italian Ministry of Agriculture (Min. Decr. 20.04.1982) and considered of a certain importance in the local economy. Desiree is a commercial cultivar grown throughout the major agricultural areas of Italy, and it is drought resistant. Flowering time was recorded by counting the percentage of open flowers until the end

Table 1. Field elevation (m) and geographical coordinates for the four experimental sites located at Pesche, Molise Region, Italy.

\begin{tabular}{lccc} 
Field number & Elevation (m) & Northing & Easting \\
1 & 590 & $41^{\circ} 36.350$ & $14^{\circ} 17.104$ \\
2 & 822 & $41^{\circ} 36.515$ & $14^{\circ} 17.724$ \\
\hline 3 & 902 & $41^{\circ} 36.919$ & $14^{\circ} 17.456$ \\
4 & 922 & $41^{\circ} 36.889$ & $14^{\circ} 17.219$ \\
\hline
\end{tabular}

Table 2. Harvesting dates for the two different Potato cultivars.

\begin{tabular}{lccc}
$\begin{array}{l}\text { Field } \\
\text { number }\end{array}$ & Sowing & Harvest & $\begin{array}{c}\text { Days from sowing } \\
\text { to harvest }\end{array}$ \\
$\begin{array}{ccc}\text { Turchesca } \\
1\end{array}$ & & \\
2 & $14 / 03 / 07$ & $29 / 07 / 07$ & 137 \\
3 & $03 / 04 / 07$ & $31 / 07 / 07$ & 119 \\
4 & $20 / 03 / 07$ & $22 / 07 / 07$ & 124 \\
Désirée & $20 / 03 / 07$ & $26 / 08 / 07$ & 159 \\
1 & & & \\
2 & $14 / 03 / 07$ & $27 / 07 / 07$ & 135 \\
3 & $03 / 04 / 07$ & $03 / 08 / 07$ & 122 \\
4 & $20 / 03 / 07$ & $08 / 08 / 07$ & 141 \\
\hline
\end{tabular}

Table 3. Vegetation indices used in the study.

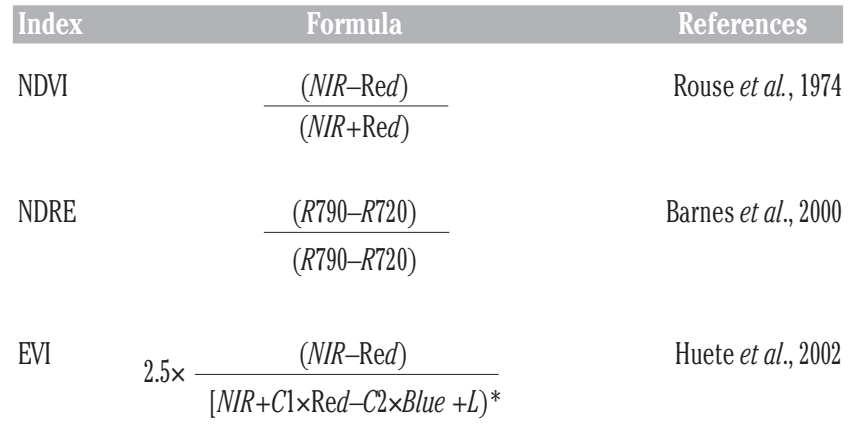

TVI $\quad 0.5 \times[120 \times(R 750-R 550)-200 \times(R 670-R 550)] \quad$ Brodge and Leblanc, 2001

MCARI $\quad\left[(R 700-R 670)-0.2 \times(R 700-R 550) \times \frac{R 700}{R 670} \quad\right.$ Daugthry et al., 2000

TCARI $3 \times[(R 700-R 700)-0.2 \times(R 700-R 550) \times(R 700 / R 670)] \quad$ Haboudane et al., 2002

$\frac{\left(1+L^{a}\right) X(R 800-R 670)}{(R 800+R 670)+L}$

Huete et al., 1988

\begin{tabular}{lll} 
MCARI/OSAVI & MCARI & Haboudane et al., 2002 \\
\hline OSAVI
\end{tabular}

La, Soil-adjustment factor set to be 0.5. NDVI, normalized difference vegetation index; NDRE, normalized difference red edge; EVI, enhanced vegetation index, TVI, triangular vegetation index; MCARI modified chlorophyll absorption reflectance index; TCARI, transformed chlorophyll absorption reflectance index; SAVI, soil-adjusted vegetation Ind. ${ }^{*}[C 1=6 ; C 2=7.5 ; L=1]$. 
of flowering and for each plot. For example, the value of $100 \%$ means that the crop reached full flowering at the end of the flowering time

Each cultivar was replicated 4 times in plots arranged in a complete randomized experimental design. Each plot was $100 \mathrm{~m} 2$. Non-destructive analyses were made in one square meter inside each plot. Leaf area was collected through non-destructive measurements by using a portable LI-COR LAI 2000 (LI-COR Biosciences, Lincoln, NE, USA) in each plot on $5^{\text {th }}$ and $13^{\text {th }}$ July 2007 . These dates were chosen as they represented the full vegetation cover stage prior to tuber harvesting.

Sowing and harvest dates and days from sowing to harvest are presented in Table 2. Before sowing the soil was tilled with a deep ploughing, followed by two harrowing. At sowing fertilization was made with $100 \mathrm{~kg} \mathrm{~N} \mathrm{ha}^{-1}, 90 \mathrm{~kg} \mathrm{P} \mathrm{ha}^{-1}$ and $200 \mathrm{~kg} \mathrm{~K} \mathrm{ha}^{-1}$. After 8-10 days from sowing, a light harrowing was made to control weeds and avoid the development of soil crust.

\section{Remote sensing}

A FieldSpec ${ }^{\circledast}$ Hand-Held Pro portable spectroradiometer (Analytical Spectral Device, Boudler, C0, USA) was used to measure the reflected light from the canopy and the soil on $5^{\text {th }}$ and $13^{\text {th }}$ July 2007 . The spectral range of the radiometer ranged from 350 to $1100 \mathrm{~nm}$ and the sensor FOV was $25^{\circ}$ and measurements were taken inside each plot. Readings were taken under clear sky conditions and converted to reflectance by referencing a $99 \%$ Spectralon (Labsphere Inc., North Sutton, NH, USA) panel at various times during each sample date. Since the aim of this study was at using indices found within the literature review, eight vegetation indices were identified and used for this study (Table 3 ).

Descriptive statistic of yield, LAI and vegetation indices and Repeated Measures ANOVA were performed with GENSTAT $10^{\text {th }} \mathrm{Ed}$. (Lawes Agricultural Trust, 2007).

\section{Results and Discussion}

Crop yield was higher for the Desiree than Turchesca, and the field at $590 \mathrm{~m}$ asl showed higher yield than the remaing two fields (Figure 1 and Table 4). Higher yields were expected at the field with elevation higher than $590 \mathrm{~m}$ because lower temperatures influence the developmental stages by increasing duration of growth allowing the crop to absorb more radiation and accumulate more biomass. The optimal temperature for potato development is around $14 / 18^{\circ} \mathrm{C}$, with a base temperature (below which crop development stops) around $6 / 8{ }^{\circ} \mathrm{C}$; therefore, it might be possible that the field located at the higher elevation had temperatures closer to the base temperature, slowing down developmental rates, and reaching flowering time later than the crops at $590 \mathrm{~m}$. In fact, Table 5 showed the developmental stage of flowering time. Turchesca showed a slower flowering time with respect to Desiree, which might have affected the final yield. For both dates of sampling, on Field 1 both cultivars reached the end of flowering with $100 \%$ of flowers opened. At Field 2 , the $5^{\text {th }}$ July 07 Turchesca had $79 \%$ of flowers opened and Desiree $81 \%$, while the $13^{\text {th }}$ July 07 both cultivar reached the end of flowering time with $100 \%$ of flowers open. At Field 3 the $5^{\text {th }}$ July 07 percentages were 77 and $81 \%$, and the values for $13^{\text {th }}$ July 07 were 92 and $96 \%$ for Turchesca and Desiree, respectively. At the highest elevation (Field 4 ) the percentage of open flowers on $5^{\text {th }}$ July 07 for Turchesca were $67 \%$ and for Desiree $69 \%$, while for $13^{\text {th }}$ July they were $90 \%$ and $94 \%$ for Turchesca and Desiree, respectively (Table 5).

LAI values are reported in Figures $2 \mathrm{a}$ and $2 \mathrm{~b}$ and its descriptive statistics in Table 4, for the two cultivars and the two sampling dates. Turchesca cultivar showed higher values than Desiree, for both sam- pling dates. The $5^{\text {th }}$ July 07 values of LAI ranged between 2.07 and 3.51 for Turchesca and between 1.7 and 2.5 for Desiree (Figure $2 \mathrm{a}$ ). The $13^{\text {th }}$ July 07 values ranged between 1.6 and 2 and 1.2 and 1.5 for Turchesca and Desiree, respectively (Figure $2 \mathrm{~b}$ ). Temperature effects slowed the development causing a different number of leaves between cultivars at different site elevation. Moreover, the presence of the Colorado potato beetle (Leptinotarsa decemlineata) caused LAI values to be lower than expected especially on Desiree since this resulted to be more sensitive to the pest infection, but the crop still

Table 4. Descriptive statistic for tuber yield and leaf area index.

\begin{tabular}{|c|c|c|c|c|}
\hline Cultivar & & $\begin{array}{c}\text { Yield } \\
\left(\mathrm{g} \mathrm{m}^{-2}\right)\end{array}$ & . & 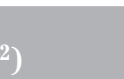 \\
\hline & & & 05-Jul-07 & 13-Jul-07 \\
\hline Turchesca & Mean & 7864.17 & 1.51 & 2.07 \\
\hline & Standard error & 4376.24 & 0.76 & 0.86 \\
\hline & Conf. Lev. (95\%) & 18829.46 & 3.28 & 3.71 \\
\hline Desiree & Mean & 17879.17 & 2.19 & 1.29 \\
\hline & Standard error & 4791.48 & 0.25 & 0.19 \\
\hline & Conf. Lev. (95\%) & 20616.09 & 1.07 & 0.81 \\
\hline
\end{tabular}

Table 5. Percentage of open flowers at the two dates of sampling for both cultivars.

\begin{tabular}{|c|c|c|c|c|c|c|c|c|}
\hline & \multicolumn{8}{|c|}{ Field elevation (m) } \\
\hline & & & & & & & & \\
\hline & $\mathrm{Tu}$ & Des & Tur & Des & Tur & Des & Tur & Des \\
\hline 05-July-07 & 100 & 100 & 79 & 81 & 77 & 81 & 67 & 69 \\
\hline 13-July-07 & 100 & 100 & 100 & 100 & 92 & 96 & 90 & 94 \\
\hline
\end{tabular}

Table 6. Significance values from ANOVA for date of samplings, field elevation and interaction between field elevation and date of sampling for Turchesca and Desiree for LAI, open flowers and yield.

\begin{tabular}{lccc} 
Cultivar & Date & Elevation & Date per elevation \\
Turchesca & & & \\
LAI & ns & 0.035 & 0.009 \\
Open flowers & 0.000 & ns & ns \\
$\quad$ Yield & $n s$ & 0.003 & $n s$ \\
Desiree & & & \\
LAI & 0.001 & $n s$ & $n s$ \\
Open flowers & 0.002 & 0.005 & $n s$ \\
Yield & $n s$ & 0.000 & $n s$ \\
\hline
\end{tabular}

ns, not significant.

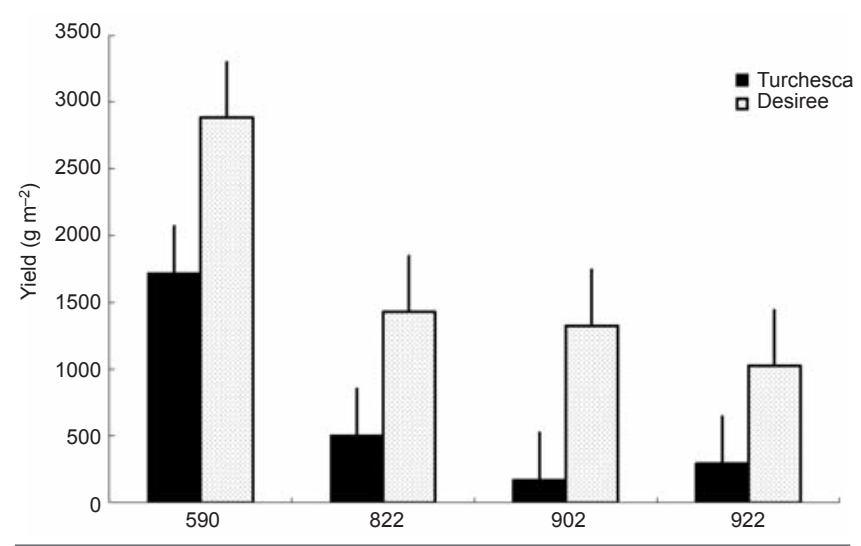

Figure 1. Potato yield $\left(\mathrm{g} \mathrm{m}^{-2}\right)$ for the two different cultivars at four field elevations. 


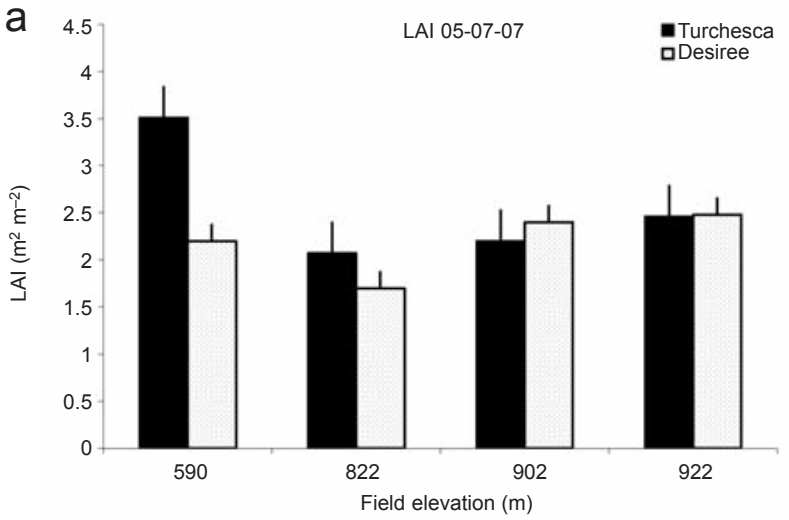

b

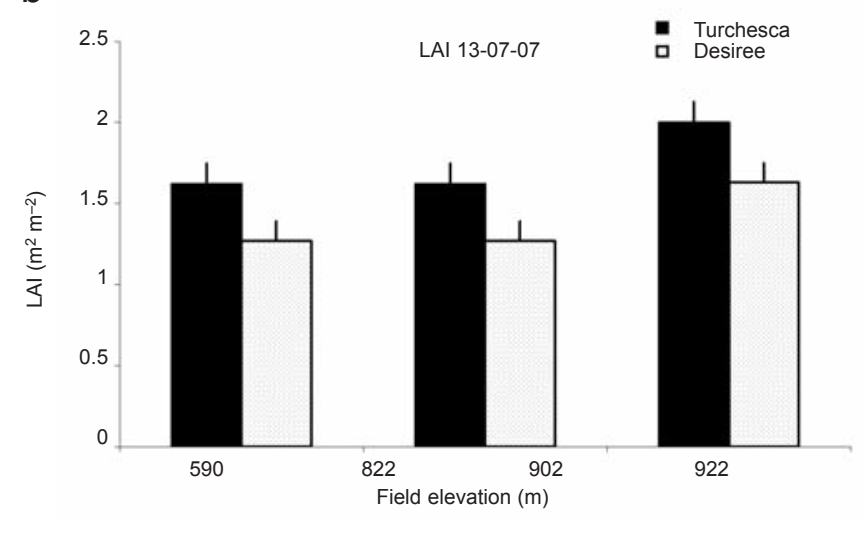

Figure 2. (a), Leaf Area Index (LAI) on 5 July 07 for the two potato cultivar at different site elevation; (b) Leaf Area Index (LAI) on 13 July 07 for the two potato cultivar at different site elevation.

Table 7. Significance values from ANOVA for date of samplings, field elevation and interaction between field elevation and date of sampling for vegetation indices.

\begin{tabular}{|c|c|c|c|}
\hline Cultivar & Date & Elevation & Date per elevation \\
\hline \multicolumn{4}{|l|}{ Turchesca } \\
\hline NDVI & ns & ns & ns \\
\hline SAVI & 0.01 & ns & 0.043 \\
\hline EVI & 0.000 & 0.18 & 0.16 \\
\hline TVI & 0.000 & ns & ns \\
\hline TCARI & 0.002 & 0.019 & 0.012 \\
\hline NDRE & ns & 0.006 & 0.019 \\
\hline MCARI & 0.004 & 0.02 & ns \\
\hline MCARI/OSAVI & 0.005 & 0.000 & 0.002 \\
\hline \multicolumn{4}{|l|}{ Desiree } \\
\hline NDVI & ns & ns & ns \\
\hline SAVI & 0.004 & 0.000 & 0.14 \\
\hline EVI & 0.009 & 0.005 & 0.008 \\
\hline TVI & 0.000 & 0.000 & 0.001 \\
\hline TCARI & 0.004 & 0.009 & 0.000 \\
\hline NDRE & 0.000 & 0.13 & ns \\
\hline MCARI & 0.006 & 0.002 & 0.001 \\
\hline MCARI/OSAVI & 0.005 & 0.000 & 0.000 \\
\hline
\end{tabular}

yielded better than the Turchesca. For the $13^{\text {th }}$ July LAI values were not available for Field 1. Table 6 shows the significance values of the Repeated Measures ANOVA test for dates, elevation, interaction between dates and elevation for the LAI, yield and percentage of open flowers, for Turchesca and Desiree, respectively. LAI was significant only for the elevation and date per elevation for Turchesca and only for the date of sampling for Desiree, and this could be due to the Colorado potato beetle presence on this cultivar. For both cultivars the percentage of open flower was significant for the date of sampling and elevation. Yield was significant for elevation, showing how the effects of temperature at different field elevation influences crop growth, development and final production.

Table 7 shows the same Repeated Measure ANOVA analysis for the VIs. For both cultivars the NDVI was not significant, confirming its limitation for cultivar discrimination. For the Desiree cultivar all the other VIs showed significant differences for dates and elevation and their interactions. This can be explained by the different morphologic and developmental behaviour of the two cultivars and their effects on crop reflectance. Both cultivars presented different leaf dimensions, different number of leaves and their distribution and distinct flowering times and number of flowers (Tables 2 and 4). Moreover the different flower colours for the two cultivars influenced the pattern of reflectance, hence vegetation indices. For instance, Desiree had white flowers while Turchseca had turquoise flowers. Turchesca had a higher leaf density, in particular it showed numerous small leaves, which covered the soil on the row between two consecutive plants, and caused a lower soil reflectance on the row, but significant soil reflectance influence between the rows. Desiree had less but bigger leaves than Turchesca and evenly distributed in layers, since this cultivar was taller than Turchesca for which, however, the overall soil coverage was lower than Desiree. The index MCARI/OSAVI discriminated each cultivar at different site elevation because the MCARI/OSAVI considers at the same time the effects of canopy growth through the depth of chlorophyll absorption $(670 \mathrm{~nm})$ relatively to the reflectance at $700 \mathrm{~nm}$, located in the red-edge portion of the spectrum and therefore sensitive to crop structural changes and $550 \mathrm{~nm}$, which has been related to canopy nutritional status (Blackmer and Schepers, 1995). In addiction, the ratio 700/600 nm was introduced with the aim of reducing soil reflectance effects, and part of the crop that do not have photosynthetic capacity. The denominator, OSAVI also is used to reduce the effects of soil reflectance for the estimation of canopy growth. On the other hand, NDVI was negatively affected by soil reflectance and crop geometry and was not able to pick any difference between the cultivar. Aparicio et al. (2000) found that NDVI lack predictive ability for specific environment/growth stages combinations so that their values as indirect genotype selection for biomass or LAI were limited.

In conclusion, the use of remotely sensed vegetation indices helped in discriminating between the two different cultivars at two different growth stages, and can be useful in quantifying crop growth and final yield. MCARI/OSAVI, TCARI and EVI better responded in discriminating the two cultivars. The EVI in particular, developed for satellites application, can be used to develop regional model of potato yield estimation and be useful to farmers' for a better agronomic field management and economic planning.

\section{References}

Aparicio N., Villegas D., Araus J.L., Casadeus J., Royo C., 2002. Relationship between growth traits and spectral vegetation indices in Durum Wheat. Crop Sci. 42:1547-1555.

Aparicio N.,Villegas D., Casadesus J., Araus J.L., Royo C., 2000. 
Spectral Vegetation Indices as Nondestructive Tools for Determining Durum Wheat Yield. Agron. J. 92:83-91.

Asrar G., Fuchs M., Kanemasu E.T., Hatfield J.L., 1984. Estimating absorbed photosynthetic radiation and LAI from spectral reflectance in durum wheat. Agron. J. 76:300-306.

Baret F., Guyot G., 1991. Potentials and limits of vegetation indices for LAI and APAR assessment. Rem. Sens. Environ. 35:161-173.

Barnes E.M, Clarke T.R., Richards S.E., 2000. Coincident detection of crop water stress, nitrogen status and canopy density using ground based multispectral data. In: P.C. Robert, R.H. Rust, W.E. Larson (eds), Proc. 5th Int. Conf. on precision agriculture, Madison, WI, USA.

Basso B., Cammarano D., Chen D., Cafiero G., Amato M., Bitella G., Rossi R., Basso F., 2009. Landscape position and precipitation effects on spatial variability of wheat yield and grain protein in Southern Italy. J. Agron. Crop Sci. 195:301-312.

Blackmer T.M., Schepers J.S., 1995. Use of a chlorophyll meter to monitor nitrogen status and schedule fertigation for corn. J. Prod. Agric. 8:56-60.

Broge N.H., Leblanc, E., 2000. Comparing prediction power and stability of broadband and hyperspectral vegetation indices for estimation of green leaf area index and canopy chlorophyll density. Remote Sens. Environ. 76:156-172.

Daughtry C.S.T., Walthall C.L., 1998. Spectral discrimination of Cannabis sativa L. leaves and canopies. Remote Sens. Environ. 64:192-201.

Daughtry C.S.T., Walthall C.L., Kim M.S., de Colstoun E.B., McMurtrey III J. E., 2000. Estimating Corn Leaf Chlorophyll Concentration from Leaf and Canopy Reflectance. Remote Sens. Environ. 74 229239.

Demetriades-Shah,T.H., Steven M.D., Clark J.C., 1990. High resolution derivative spectra in remote sensing. Remote Sens. Environ. 33:55-64.

Galvao L.S., Formaggio A.R., Tisot D.A., 2005. Discrimination of sugarcane varieties in Southeastern Brazil with E0-1 Hyperion data. Remote Sens. Environ. 94:523-534.

Galvao L.S., Roberts D.A., Formaggio A.R., Numata I., Breuning F.M., 2009. View angle effects on the discrimination of soybean vari- eties and on the relationships between vegetation indices and yield using off-nadir Hyperion data. Remote Sens. Environ. 113:846-856.

Haboudane D., Miller J.R., Tremblay N., Zarco-Tejada P.J., Dextraze L., 2002. Integrated narrow-band vegetation indices for prediction of crop chlorophill content for application to precision agriculture. Remote Sens. Environ. 81:416-426.

Huete A.R., 1988. A soil adjusted vegetation index (SAVI). Remote Sens. Environ. 25:295-309.

Huete A.R., Jackson R.D., Post D.F., 1985. Soil background effects on canopy reflectance. Remote Sens. Environ. 17:37-53.

Inoue Y., 2003. Synergy of remote sensing and modeling for estimating ecophysiological processes in plant production. Plant Prod. Sci. 6:3-16.

Lawes Agricultural Trust, 2007. GenStat 10th edition, ver. 10.1. Lawes Agricultural Trust. VSN International, Hemel Hempstead, UK.

Li, H., Lascano, R.J., Barnes, E.M., Booker, J., Wilson, L.T., Bronson, K.F., Segarra, E., 2001. Multispectral reflectance of cotton related of plant growth, soil water and texture, and site elevation. Agron. J. 93:1327-1337.

Pfeiffer T.W., 1996. Choosing soybean varieties from yield trials: multiple maturity groups and yield variability. J. Prod. Agric. 9:371376.

Qi J., Chehbouni A., Huete A.R., Kerr Y.H., Sorooshian S., 1994. A modified soil adjusted vegetation index. Remote Sens. Environ. 48:119-126.

Rondeaux G., Steven M., Baret F., 1996. Optimization of soil-adjusted vegetation index. Remote Sens. Environ. 55:95-107.

Thenkabail, P.S., 2002. Optimal hyperspectral narrow bands for discriminating agricultural crops. Remote Sens. Environ. 20:257291.

Wiegand C.L., Gerbermann A.H., Gallo K.P., Blad B.L., Dusek D., 1990. Multisite analyses of spectral-biophysical data for corn. Remote Sens. Environ. 33:1-16.

Zhu Y., Tian Y., Yao X., Liu X., Cao W., 2007. Analysis of common canopy reflectance spectra for indicating leaf nitrogen concentrations in wheat and rice. Plant Prod. Sci. 10:400-411. 